\title{
Research on the image of sweeping robot based on the Artificial Neural Network
}

\author{
Chang Song ${ }^{1, a^{*}}$, Yoshito Ogata ${ }^{2}$ \\ ${ }^{1}$ Kyushu University, Graduate School of Design, Japan, and Sichuan University of Media and Communications, China \\ ${ }^{2}$ Kyushu University, Faculty of Design, Japan
}

\begin{abstract}
Based on the theory of Artificial Neural Network and Kansei Engineering, the image of sweeping robots are formed using the content analysis method, and propose four kinds of sweeping robot as the experimental samples, which have a strong influence on the market. The image questionnaires are compiled by the semantic differences methods. 200 office workers, half men and half women, are chose as the survey respondents. And use SPSS statistical software for data analysis. Afterwards, the BP Artificial Neural Network model is established by Matlab based on the questionnaire results, and the optimized design scheme with image feature combination for sweeping robot products is generated on the basis of BP Artificial Neural Network model. This study construct the emotional demands on the image level, and carry out experiments and statistical analysis, which lays a solid foundation for the study of product image in theory and approach.
\end{abstract}

Keywords. Artificial Neural Network, Image, Sweeping Robot, Kansei

\section{Introduction}

With the development of human society, most parts of life and time are occupied by heavy work. In order to lighten the burden on people' life, the sweeping robots are gradually used to help people do housework. Many kinds of sweeping robot brands appearing on the market, only Jingdong mall has more than 60 brands on sale. Moreover, the more and more diversified and personalized trends are formed to meet the needs of people. And the product image is an effective way to express the people's needs. For a long time, designers are relying on their own experience, intuition and inspiration to solve the problem of product image without the effective theoretical and experimental support. it is difficult to accurately and efficiently meet the emotional needs of consumers.

The image questionnaire was compiled by the content analysis and emantic differences methods based on the theory of Artificial Neural Networks and Kansei Engineering in this study. And use SPPSS statistical software for data analysis. Afterwards, the BP Artificial Neural Network model is established by Matlab, and he optimized image design scheme for sweeping robots are generated as references for the products image of sweeping robots, and lay a sound foundation for the product image.

\section{Theory discussion}

\footnotetext{
* Corresponding author: schang025@163.com (Chang Song)
}

\subsection{Discussion on image}

First of all, it must make a connection between "image" and the "Kansei Engineering". In the aspect of significance, (In a sense), the "sensibility" is an important part of the study of Kansei Engineering ", which is exactly matched with the" image ". The former belongs to philosophy, and the process is the focus of the research.

While the latter is part of psychological aspects, which is used for referring to psychological characteristics. Secondly, the clear boundaries are not observed between the" image "and" Kansei Engineering ", both have the ability to present the audience' emotion to the products.

The image is a mental image, and it is the merged crystallization between subjective mind image and environmental factors. Sometime, it is the results of the combination between instantaneous feeling and past experiences. The investigated image involves feeling, perception, style and other areas. Figure 1 shows the image formation process.

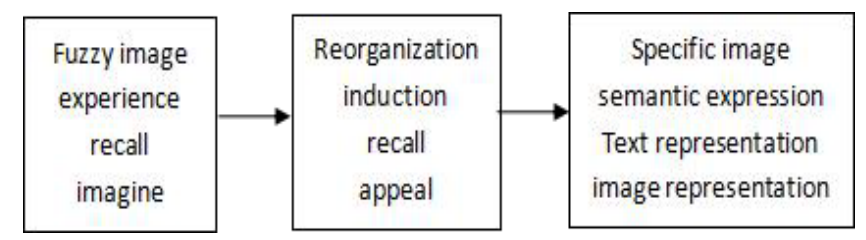

Fig. 1. Process of image formation 
In conclusion, the image can be interpreted as the formed mental imagery based on past experience or feel in their situation. It may be an intuitive response or the memory of past experience. In the design process, the purpose of design image is giving the product image according to the users' demand for products, feeling and thoughts. Product image is formed gradually through the users' perceptual cognition. It can be divided into function, structure, shape, color, material and other aspects. Generally, the product images need to be conveyed based on the needs and feelings of people. The studies on the preference of sweeping robots' image is an important communicating bridge between designers and consumers, which will greatly give the designers much assistance and hints.

\subsection{Artificial Neural Networks}

Artificial Neural Networks, abbreviated as neural networks or artificial neural network, is an information processing system for imitating the biological function of the nervous system. The network consists of input layer, output layer and the hidden layer, as shown in the figure 2.

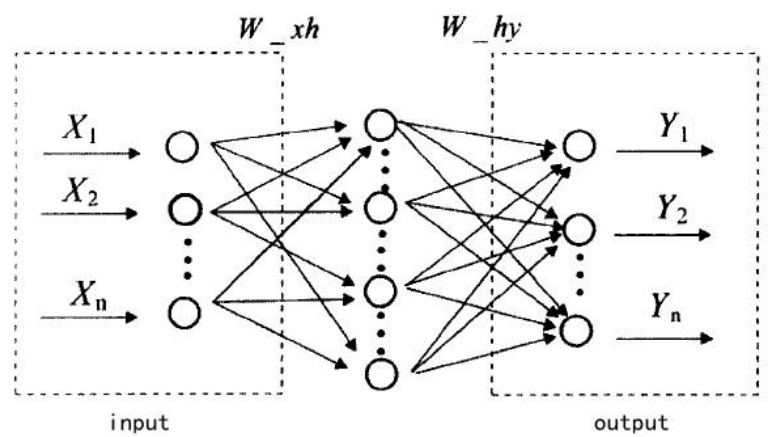

Fig. 2. Artificial Neural Networks of systems

The BP artificial neural network is supervised. Among the study of artificial neural network, learning and memory is the two main parts its basic framework is multilayer network, and multilayer architecture is to increase the nonlinearity, hence it can handle nonlinear problems which cannot be rendered by regression analysis. The BP artificial neural network can be realized with MATLAB programming for forecasting and fitting, and the function is very powerful. In recent years, in terms of product design, design and research personnel will transfer the application into perceptual design through the computer simulation, and the preferences, product function, form and color for users are investigated systematically. The product image is presented in a structured way.

\section{Research method}

This paper determines the dimensions of the sweeping robot image and extraction of experimental samples through content analysis methods, the drafting group measured and the image questionnaire by the semantic differential method; statistical analysis proceeds using
SPSS; finally, Matlab is used to establish BP Artificial Neural Network model in order to accomplish the image design.

\subsection{The sample and the tested population}

According to the content analysis method, the image of sweeping robot is divided into function, structure, shape, color and material image space. Meanwhile, the highest acceptability price (1688 - $2340 \mathrm{RMB})$ is selected from the Jingdong mall, and the four types of sweeping robot are chose from four brands based on the sales volumes, as presented in table 1 .

Table 1. The sweeping robot.

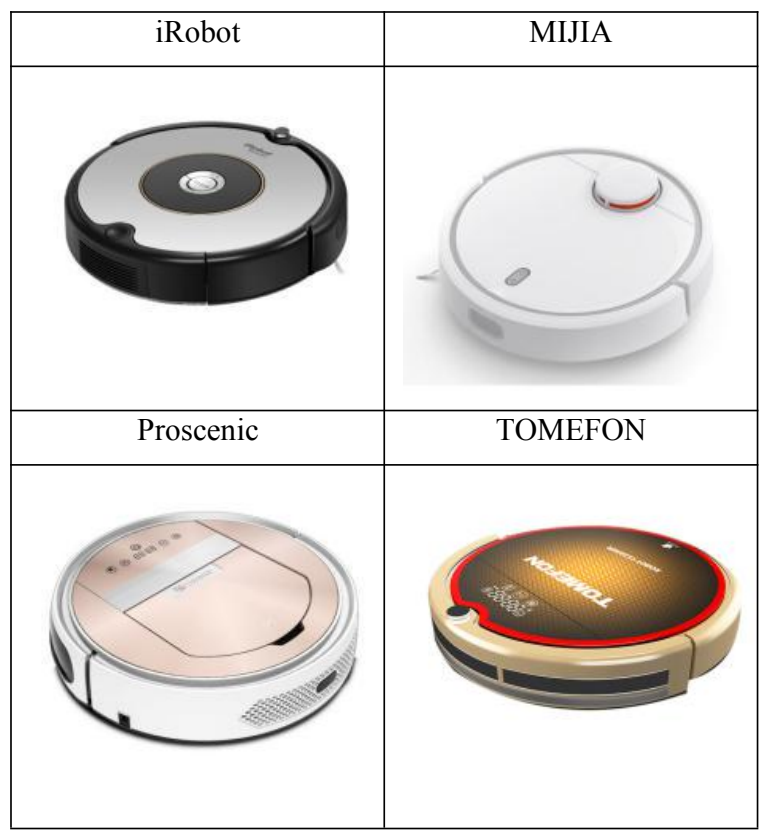

The young people who are usually busy working make up the majority of the sweeping robot users. Therefore, 200 office workers, half men and half women, are chose as the survey respondents to explore the sweeping robot image.

\subsection{Image Questionnaire}

This study is based on Kansei Engineering and image in product design, and the adjective phrases of each image space are obtained by the semantic differential method, as shown in Table 2. Likert 5 point scale is applied to assess the opposite words, and interval scale scores were expressed in 2,1,0,1 and 2, respectively.

Table 2. Adjective with image .

\begin{tabular}{|c|c|}
\hline Functional image & Structural image \\
\hline Novel \& obsolete & Stable \& adjustable \\
\hline Versatile \& single & Firm \& loose \\
\hline $\begin{array}{l}\text { Easy to use \& } \\
\text { difficult to use }\end{array}$ & Independent \& systematic \\
\hline
\end{tabular}




\begin{tabular}{|c|c|}
\hline Intelligent \& rigid & Complex \& concise \\
\hline Suitable \& absurd & Dangerous\& Safe \\
\hline Morphological image & Color image \\
\hline Beautiful \& ugly & Passionate \& callous \\
\hline $\begin{array}{c}\text { Science fiction \& } \\
\text { reality }\end{array}$ & Dull \& bright \\
\hline Round \& sharp & Simple \& fancy \\
\hline Unique \& common & Gorgeous \& artless \\
\hline Complex \& concise & Warm \& cold \\
\hline Material image & \\
\hline Good \& poor & \\
\hline Hard \& soft & \\
\hline Durable \& easy to break & \\
\hline Smooth \& rough & \\
\hline Elegant \& vulgar & \\
\hline
\end{tabular}

\subsection{Statistical analysis}

After the questionnaires are collected, the scores are coded and the 2,1,0,1,2 are changed into 1,2,3,4,5 in sequence. The One-sample $\mathrm{T} T$ test is used to verify five images of the data through statistical software SPSS to obtain the significance and the bias analysis of image phrases.

\subsection{BP Artificial Neural Network model}

The BP Artificial Neural Network model is established by Matlab based on the results of the image questionnaires. Learning and recalling, analyzing and establishing the image data model, provide a data validation model for the design of new products.

\section{Results and Discussion}

\subsection{One-sample $\mathrm{T}$ test}

200 young workers, half men and half women are questioned to obtained the data. The 200 valid questionnaires are analyzed by statistical software SPSS. One-sample $\mathrm{T}$ test is carried out on the five space images of the sweeping robots .

According to the results of One-sample $\mathrm{T}$ test of the sweeping robot image spaces (Table 3 ), we can know that the adjective vocabulary is significant, and the function of image is novel, versatile, easy to use, intelligent, suitable image (the versatile aspect is the most significant, $\mathrm{M}=1.710)$.
The image of structure tends to be stable, firm, systematic, concise, safe (the firm aspect is the most significant, $\mathrm{M}=1.530)$.

The image of morphological tends to be beautiful, science fiction, round, common, concise (the aspect of science fiction is the most significant, $\mathrm{M}=1.600$ ).

The image of color space tends to be passionate, bright, simple, gorgeous, warm (the passionate aspect is the most significant, $\mathrm{M}=1.985$ ).

Finally, the image of material tends to be superior, hard, durable, smooth, elegant (the durable aspect is more significant, $\mathrm{M}=1.420$ ).

Table 3. One-Sample Test

\begin{tabular}{|c|c|c|c|}
\hline Image & Adjective with image & M & Sig. \\
\hline \multirow[t]{5}{*}{ Functional } & Novel \& obsolete & 2.205 & $0.000 * * *$ \\
\hline & Versatile \& single & 1.710 & $0.000 * * *$ \\
\hline & $\begin{array}{l}\text { Easy to use \& } \\
\text { difficult to use }\end{array}$ & 2.020 & $0.000^{* * *}$ \\
\hline & Intelligent \& rigid & 2.235 & $0.000 * * *$ \\
\hline & Suitable \& absurd & 1.740 & $0.000 * * *$ \\
\hline \multirow[t]{5}{*}{ Structural } & Stable \& adjustable & 1.815 & $0.000 * * *$ \\
\hline & Firm \& loose & 1.530 & $0.000^{* * *}$ \\
\hline & $\begin{array}{c}\text { Independent \& } \\
\text { systematic }\end{array}$ & 4.230 & $0.000 * * *$ \\
\hline & Complex \& concise & 4.000 & $0.000 * * *$ \\
\hline & Dangerous\& Safe & 4.330 & $0.000 * * *$ \\
\hline \multirow[t]{5}{*}{$\begin{array}{c}\text { Morpholog } \\
\text { ical }\end{array}$} & Beautiful \& ugly & 1.760 & $0.000 * * *$ \\
\hline & Science fiction \& reality & 1.600 & $0.000 * * *$ \\
\hline & Round \& sharp & 2.360 & $0.000 * * *$ \\
\hline & Unique \& common & 4.000 & $0.000 * * *$ \\
\hline & Complex \& concise & 4.305 & $0.000 * * *$ \\
\hline \multirow[t]{5}{*}{ Color } & Passionate \& callous & 1.985 & $0.000 * * *$ \\
\hline & Dull \& bright & 3.615 & $0.000 * * *$ \\
\hline & Simple \& fancy & 2.375 & $0.000 * * *$ \\
\hline & Gorgeous \& artless & 2.365 & $0.000 * * *$ \\
\hline & Warm \& cold & 2.060 & $0.000 * * *$ \\
\hline \multirow[t]{5}{*}{ Material } & Good \& poor & 1.825 & $0.000 * * *$ \\
\hline & Hard \& soft & 2.525 & $0.000 * * *$ \\
\hline & Durable \& easy to break & 1.420 & $0.000 * * *$ \\
\hline & Smooth \& rough & 1.895 & $0.000 * * *$ \\
\hline & Elegant \& vulgar & 1.950 & $0.000 * * *$ \\
\hline
\end{tabular}




\subsection{Artificial Neural Network}

Transfer the average value of $\mathrm{M}$ obtained by the statistical software SPSS into the interval $(0,1)$. Afterwards, using Matlab as a BP artificial neural network training software, the image $M$ value is trained and input into program until the BP artificial neural network convergence is obtained. Then the sweeping machine image data model can be established and the image database is constructed completely, which provide the data model for the new products verification.

Firstly, the Excel data table is set up with the average value of the single sample T test, and P1, P2, P3 and P4 are used to represent the four sweeping robot samples. Then the data is input into the Matlab program again, and the initial eigenvalue is obtained to prepare for normalization.

Then, the feature matrix is normalized, and the normalized command program is input into the Matlab program command box:

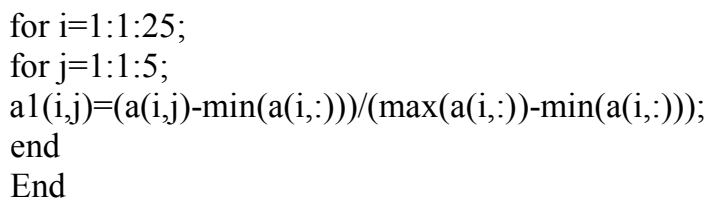

Thus, the normalized values of 25 image eigenvalues are obtained, And then the BP artificial neural network is established. The detailed program coding was as follows:

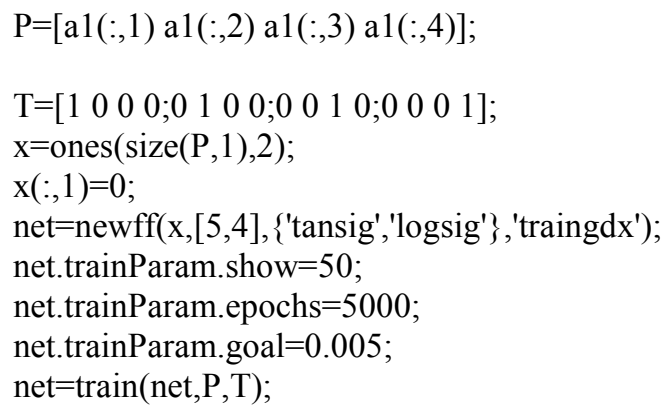

The main process of Matlab Net is the new BP artificial neural network. The training process report is shown in Figure 3, and it presents that the BP artificial neural network convergence can be observed clearly. Figure 4 shows the training convergence curve of $\mathrm{BP}$ artificial neural network is continuous, and finally tend to a point, the image data model of the BP artificial neural network is established completely.

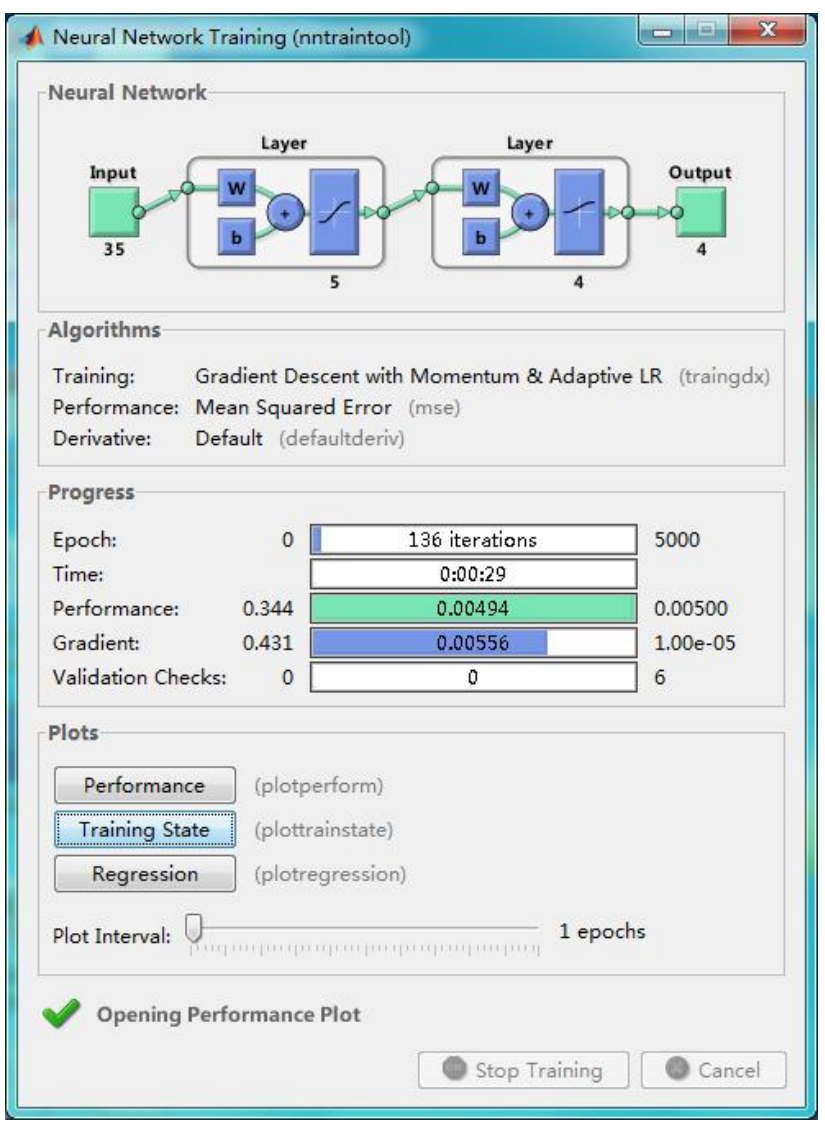

Fig. 3. Training process report chart.

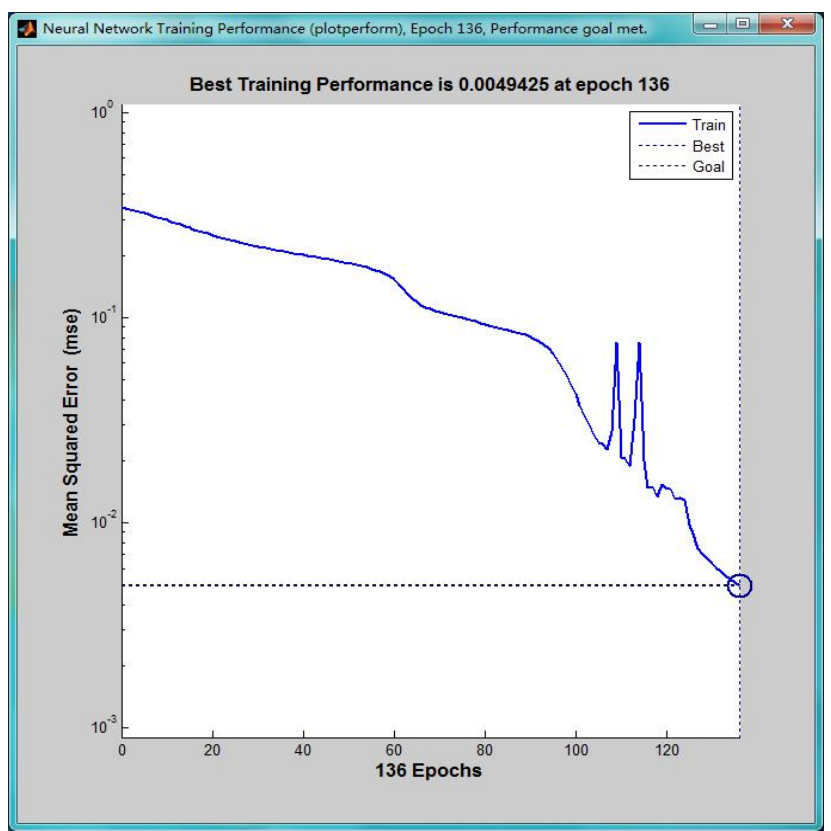

Fig. 4. Training convergence.

\section{Conclusion}

In summary, the four kinds of sweeping robots are selected as the experimental samples. And the Onesample $\mathrm{T}$ test is conducted by SPSS based on the theory of Kansei Engineering, and then Matlab are used to establish BP artificial neural network image model, 
which will provide a reference for the study of sweeping robot product image.

\section{Acknowledgements}

Supported by China Scholarship Council (CSC).

\section{References}

1. Hung-Yuan Chen, Yu-Ming Chang, Extraction of product form features critical to determining consumers' perceptions of product image using a numerical definition-based systematic approach, International Journal of Industrial Ergonomics $39,133-145(2009)$

2. Nagamachi, M., Kansei engineering and comfort. International Journal of Industrial Ergonomics 19 (2), 79-80(1997)

3. Nagamachi, M., Kansei engineering as a powerful consumer-oriented technology for product development. Applied Ergonomics 33 (3) ,298-294 (2002)

4. Crilly, N., Moultrie, J., Clarkson, P.J., Seeing things: consumer response to the visual domain in product design. Design Studies 25 (6), 547-577 (2004)

5. S. Bornholdt and D. Graudenz. General asymmetric neural networks and structure design by genetic algorithms. Neural Networks, 5:327-334,(1992)

6. L Liu ,M Deng,An Evolutionary Artificial Neural Network Approach for Breast Cancer Diagnosis,International Conference on Knowledge Discovery\& Data Mining , 25 (3) :593-596(2010)

7. L Liu ,M Deng,An Evolutionary Artificial Neural Network Approach for Breast Cancer Diagnosis,International Conference on Knowledge Discovery\& Data Mining , 25 (3) :593-596(2010)

8. Chang Song ,Chen Tien-li,Image Study of Longstanding universities based on international students - In National Taipei University of Technology's case,2011 IEEE the 12th International Conference on Computer-aided Industrial Design \& Conceptual Design, 211-215(2011) 